\title{
Relation between Body Mass Index, Waist Circumference, and Echocardiographic Index of Left Ventricular Diastolic Function (Korean J Obes 2016;25:84-91)
}

\author{
Yoon Jeong Cho, Geon Ho Lee* \\ Department of Family Medicine, Catholic University of Daegu School of Medicine, Daegu, Korea
}

The prevalence of obesity is increasing worldwide, and it is a major health issue because of its association with morbidity, mortality, and cardiovascular disease. ${ }^{1,2}$ Obesity is an independent risk factor for development of heart failure (HF) in the general population, and being overweight also increases the risk for $\mathrm{HF}^{3,4}$

Diastolic dysfunction is a relatively common cardiac condition and it contributes significantly to the development of HF in obese patients even in the presence of preserved systolic function. ${ }^{5}$

Readers asked whether any other cardiac function parameter except E/E' was associated with central obesity. We evaluated early peak mitral inflow velocity (E), late peak mitral inflow velocity (A), E/A ratio, deceleration time (DT), early diastolic mitral annulus motion velocity (E'), late diastolic mitral annulus motion velocity (A') as predictors of left ventricular diastolic function. Of these, late peak mitral inflow velocity (A) and late diastolic mitral annulus motion velocity (A') were positively associated with central obesity after adjusting for age, body mass index, systolic blood pressure ( $P$ value $<0.05)$. The other reader question was about the association between central obesity and markers of cardiac function by body mass index (BMI) category. The results from this study showed there were different results by BMI group. For the normal BMI group $(\mathrm{N}=141)$, there was no significant association between abdominal obesity and diastolic function parameters. For overweight groups $(\mathrm{N}=123)$, early peak mitral inflow velocity $(\mathrm{E})$ and E/A ratio were significantly associated with abdominal obesity $(P$ value $<0.001, P$ value $=0.008$, re- spectively). For the obesity group $(\mathrm{N}=126)$, only the E/E' ratio was significantly associated with abdominal obesity.

As a reader mentioned, some recent studies have shown that being overweight is associated with better HF prognosis. ${ }^{6}$ A recent metaanalysis showed BMI and mortality were related to HF. This metaanalysis showed that being overweight and obese were associated with lower all-cause and cardiovascular mortality rates in patients with HF but were not associated with increased mortality in any included study. Obesity was a key risk factor for developing HF. But the prognostic significance of obesity in the case of established HF was not clear.

Even if diastolic dysfunction was slightly developed, it did not reflect increasing HF mortality or morbidity. Our study included only healthy obese people who were categorized with Asia-Pacific obesity criteria. This group might not show a bad prognosis after long term follow-up. Therefore I totally agree with the opinion that in the future a large scale prospective study should be undertaken.

\section{Conflicts of Interest}

There are no conflicts of interest.

\section{References}

1. Prospective Studies Collaboration, Whitlock G, Lewington S,
*Corresponding author Geon Ho Lee (iD http://orcid.org/0000-0003-0696-3804 Department of Family Medicine, Catholic University of Daegu School of Medicine, 33 Duryugongwon-ro 17-gil, Nam-gu, Daegu 42472, Korea

Tel +82-53-650-4123 Fax +82-53-650-4122 E-mail totoslee@cu.ac.kr
Copyright (C) 2016 Korean Society for the Study of Obesity

(c) This is an Open Access article distributed under the terms of the Creative Commons Attribution Non-Commercial License (http://creativecommons.org/licenses/by-nc/4.0/) which permits unrestricted non-commercial use, distribution, and reproduction in any medium, provided the original work is properly cited. 
Sherliker P, Clarke R, Emberson J, et al. Body-mass index and cause-specific mortality in 900000 adults: collaborative analyses of 57 prospective studies. Lancet 2009;373:1083-96.

2. Murphy NF, MacIntyre K, Stewart S, Hart CL, Hole D, McMurray JJ. Long-term cardiovascular consequences of obesity: 20-year follow-up of more than 15000 middle-aged men and women (the Renfrew-Paisley study). Eur Heart J 2006;27:96-106.

3. Kenchaiah S, Evans JC, Levy D, Wilson PW, Benjamin EJ, Larson MG, et al. Obesity and the risk of heart failure. N Engl J Med 2002; 347:305-13.

4. Loehr LR, Rosamond WD, Poole C, McNeill AM, Chang PP, Fol- som AR, et al. Association of multiple anthropometrics of overweight and obesity with incident heart failure: the Atherosclerosis Risk in Communities study. Circ Heart Fail 2009;2:18-24.

5. Galinier M, Pathak A, Roncalli J, Massabuau P. Obesity and cardiac failure. Arch Mal Coeur Vaiss 2005;98:39-45.

6. Vest AR, Wu Y, Hachamovitch R, Young JB, Cho L. The heart failure overweight/obesity survival Pparadox: the missing sex link. JACC Heart Fail 2015;3:917-26.

7. Oreopoulos A, Padwal R, Kalantar-Zadeh K, Fonarow GC, Norris CM, McAlister FA. Body mass index and mortality in heart failure: a meta-analysis. Am Heart J 2008;156:13-22. 